Jurnal Media Pertanian, 6(2) Oktober 2021, pp.74-79

Media Komunikasi Hasil Penelitian dan Review Literatur Bidang Ilmu Agronomi

ISSN 2503-1279 (Print) | ISSN 2581-1606 (Online) | DOI 10.33087/jagro.v6i2.124

Publisher by : Program Studi Agroteknologi Fakultas Pertanian Universitas Batanghari

\title{
Karakteristik Mutu Organoleptik Seduhan Bubuk Kopi Robusta (Coffea canephora) Pada Suhu Penyangraian Yang Berbeda
}

\author{
${ }^{*}$ Ridawati Marpaung, ${ }^{1}$ Hayata, dan ${ }^{2}$ Yuni Putri Ayu \\ ${ }^{1}$ Program Studi Agroklimatologi Fakultas Pertanian Universitas Batanghari \\ ${ }^{2}$ Alumni Program Studi Agroklimatologi Fakultas Pertanian Universitas Batanghari \\ Jl. Slamet Riyadi, Broni Jambi,36122. Telp.+620741-60603 \\ ${ }^{* 1}$ e-mail korespondensi : marpaungridawati@yahoo.com
}

\begin{abstract}
This research was aimed to know organoleptic quality characteristics of robusta coffee ( Coffea canephora) brewing on different roasting temperatures. Implementation treatment and organoleptic tests this research at the Faculty of Agriculture UNBARI Jambi in March-August 2021. The environmental design used in this study was a completely randomized design. The treatment design consisted of different roasting temperatures, with 4 levels of roasting temperature, as follows: $p 1=$ roasted at $180^{\circ} \mathrm{C} ; \mathrm{p} 2=$ roasted with a temperature of $200^{\circ} \mathrm{C} ; \mathrm{p} 3=$ roasted at a temperature of $220^{\circ} \mathrm{C}$ and $p 4=$ roasted at a temperature of $240^{\circ} \mathrm{C}$. Each treatment was repeated 3 times so that there were 12 experimental units. The observed variables of steeping coffee grounds in this research were : color, aroma, taste, bitterness, while pH and water content observed of coffee grounds. To see the effect of different roasting temperatures, statistical analysis was carried out: the variables of color, aroma, taste, bitterness, and preference were carried out by a perception test with a 5-scale Likert scale then tabulated the data, followed by analysis of variance, then continued with the DNMRT test at level $5 \%$. While testing the pH and moisture content of coffee grounds was analysis of variance and further test of DNMRT at the level of 5\%.Roasting coffee beans at a temperature of $240{ }^{\circ} \mathrm{C}$, resulted in the highest organoleptic assessment of brewing coffee grounds in terms of color, aroma, taste, bitterness, preference, pH, and water content.
\end{abstract}

Keywords: Liberika coffee, roasting temperature, organoleptic quality, brewed coffee powder.

\begin{abstract}
Abstrak. Tujuan penelitian ini adalah untuk mngetahui karakteristik mutu organoleptik seduhan bubuk kopi Robusta (Coffea canephora) dengan metode penyangraian pada suhu yang berbeda. Pelaksanaan percobaan dan uji organoleptik dalam penelitian ini dilakasanakan di Fakultas Pertanian UNBARI Jambi pada bulan Maret - Agustus 2021. Rancangan lingkungan yang digunakan pada penelitian ini adalah Rancangan Acak Lengkap Rancangan perlakuan yaitu suhu penyangraian yang berbeda, dengan 4 taraf suhu penyangraian, sebagai berikut : $\mathrm{p} 1=$ disangrai dengan suhu $180^{\circ} \mathrm{C} ; \mathrm{p} 2=$ disangrai dengan suhu $200^{\circ} \mathrm{C} ; \mathrm{p} 3=$ disangrai dengan suhu $220^{\circ} \mathrm{C}$ dan $\mathrm{p} 4=$ disangrai dengan suhu $240^{\circ} \mathrm{C}$. Setiap perlakuan dilakukan pengulangan sebanyak 3 kali sehingga terdapat 12 unit percobaan. Peubah yang diamati dari seduhan bubuk kopi dalam penelitian ini adalah : warna, aroma, citarasa, kepahitan, sedangkan peubah $\mathrm{pH}$ dan kadar air dianalisis dari bubuk kopi. Untuk melihat pengaruh lama suhu penyangraian yang berbeda dilakukan analisis statistika :peubah warna, aroma, citarasa, kepahitan, dan kesukaan dilakukan dengan uji persepsi dengan skala Likert 5 skala kemudian ditabulasi data, dilanjutkan dengan analisa ragam, kemudian dilanjutkan dengan uji DNMRT pada taraf $\alpha 5 \%$. Pengujian $\mathrm{pH}$ dan kadar air bubuk kopi dengan analisis ragam dan uji lanjut DNMRT pada taraf $\alpha 5 \%$. Dari hasil penelitian diperoleh bahwa penyangraian biji kopi pada suhu $240^{\circ}$ $\mathrm{C}$, menghasilkan penilaian organoleptik tertinggi pada seduhan bubuk kopi baik dari warna, aroma, citarasa, kepahitan, kesukaan, $\mathrm{pH}$, dan kadar air.
\end{abstract}

Kata kunci : Kopi Liberika, suhu penyangraian, Mutu organoleptik, seduhan bubuk kopi.

\section{PENDAHULUAN}

Kopi (Coffea sp), merupakan salah satu komoditas ekspor penting dari Indonesia. Kopi robusta (Coffea canephora) dimasukkan ke Indonesia pada tahun 1900. Kopi ini ternyata tahan terhadap penyakit karat daun, dan memerlukan sayarat tumbuh dan pemeliharaannya yang ringan, sedang produksinya jauh lebih tinggi. Oleh karena itu kopi ini berkembang dengan cepat. Saat ini lebih dari $90 \%$ dari areal pertanaman kopi Indonesia terdiri dari kopi robusta (Prastowo dkk, 2010).).

Kopimerupakansalahsatukomoditasdarihasilpertanian yang dipergunakan sebagaibahan baku pada industri makanan dan minuman.Hasil olahan kopiyang saatinisedang banyak dipergunakan adalah sajian minuman di café ataucoffeeshop. Keberadaanbiji kopiyang bermutu saatinisangatdihargaitinggi oleh pasar,yang bukanhanya dalam negerinamun juga internasional. Menyangrai (roasted) kopiadalah proses menggoreng kopi tanpa menggunakan minyak. Penyangraiankopi pada dasarnya merupakan proses pengubahan kimiawidan fisikalitas daripropertikopi,dalam haliniadalaharoma,rasa asam dan berbagai perisayangadadikopi.

Buah kopi yang telah dipanen memerlukan suatu proses yang sangat panjang sebelum menjadi minuman yang dapat dinikmati. Tahapan pengolahan kopi dapat digolongkan menjadi dua yaitu pengolahan kopi primer dan sekunder. Proses pengolahan kopi sekunder adalah proses penyangraian, pendinginan dan penggilingan. Dalam tahap ini, penyangraian merupakan kunci dari proses produksi kopi bubuk. Penyangraian merupakan kesatuan operasi yang sangat penting untuk mengembangkan sifat organoleptik spesifik (aroma, rasa dan warna) yang mendasari kualitas 
kopi, namun demikian, proses ini sangat kompleks, karena jumlah panas yang dipindahkan ke biji sangat penting (Mulato et al, 2006).

Proses penyangraian biji kopi dapat mempengaruhi kualitas bubuk kopi yang dihasilkan. Waktu sangrai ditentukan atas dasar warna biji kopi sangrai atau sering disebut derajat sangrai. Berdasarkan suhu penyangraian yang digunakan, kopi sangrai dibedakan atas 3 golongan yaitu light roast, medium roast, dan dark roast. Metode high temperatur long time (dark roast) menyimpulkan bahwa terjadi penurunan kelembaban pada biji kopi dari $11 \%$ menjadi $3,2 \%$ selama 14 menit penyangraian. Pengabean (2012) menyatakan suhu yang diperlukan dalam menyangrai kopi sekitar $60^{\circ} \mathrm{C}-250^{\circ} \mathrm{C}$. Sementara itu, lama waktu menyangrai cukup bervariasi, bergantung pada sistem dan tipe mesin penyangrai yang digunakan. Umumnya, waktu yang diperlukan untuk proses penyangraian sekitar 15-30 menit yang bertujuan untuk menjaga kualitas kopi dari segi warna kopi dan yang paling penting dari segi rasa kopi yang diinginkan. Hasil penelitian Agustina et al., (2019) menyatakan bahwa penyangraian kopi arabika yang banyak disukai panelis adalah kopi yang disangrai pada suhu $200^{\circ} \mathrm{C}$ dengan lama penyangraian 10 menit. Sedangkan hasil penelitian Bukhori Thomas Edvan, Rachmad Edison dan Made Same (2016), mendapatkan hasil penyangraian terbaik menggunakan suhu $190^{\circ} \mathrm{C}$, berat kopi $300 \mathrm{~g}$ dan lama waktu 10 menit.

Berdasarkan uraian di atas, maka perlu dilakukan penelitian untuk menentukan suhu penyangraian yang tepat agar karakteristik mutu organoleptik seduhan bubuk kopi Robusta (Coffea canephora) sesuai dengan kesukaan konsumen.

\section{METODE PENELITIAN}

Percobaan dan uji organoleptik dalam penelitian telah dilaksanakan di Fakultas Pertanian Universitas Batanghari Jambi. Penelitian dilaksanan pada bulan Maret - Agustus 2021. Bahan yang digunakan dalam penelitian ini yaitu biji kopi robusta yang diperoleh dari petani di Kerinci, gula pasir, dan aquades. Alat yang digunakan antara lain, mesin roasting biji kopi (coffea roasting), blender (coffea grinder), ayakan 250 mesh, gelas, sendok takaran, oven, timbangan analitik, $\mathrm{pH}$ meter, kamera, dan karung goni.

Rancangan lingkungan yang digunakan pada penelitian ini adalah rancangan acak lengkap (RAL). Rancangan perlakuan yaitu suhu penyangraian yang berbeda, dengan 4 taraf suhu penyangraian, sebagai berikut : $\mathrm{p} 1=$ disangrai dengan suhu $180^{\circ} \mathrm{C} ; \mathrm{p} 2=$ disangrai dengan suhu $200^{\circ} \mathrm{C}: \mathrm{p} 3=$ disangrai dengan suhu $220^{\circ} \mathrm{C}: \mathrm{p} 4=$ disangrai dengan suhu $240^{\circ} \mathrm{C}$. Setiap perlakuan dilakukan pengulangan sebanyak 3 kali sehingga terdapat 12 unit percobaan. Setiap unit percobaan,diperlukan $300 \mathrm{~g}$ biji kopi kering. Peubah yang diamati dalam penelitian ini adalah warna, aroma, citarasa, kepahitan dan kesukaan dari seduhan bubuk kopi, pH dan kadar air bubuk kopi.

Untuk melihat pengaruh lama suhu penyangraian yang berbeda dilakukan analisis statistika :

1. Uji dengan peubah warna, aroma, citarasa, kepahitan, dan kesukaan dilakukan dengan uji persepsi dengan skala Likert 5 skala kemudian ditabulasi data, dilanjutkan dengan analisa ragam, kemudian dilanjutkan dengan uji DNMRT pada taraf $\alpha 5 \%$.

2. Analisis $\mathrm{pH}$ dan kadar air bubuk kopi dengan analisa ragam dan uji lanjut DNMRT pada taraf $\alpha 5 \%$.

\section{Warna Seduhan Bubuk Kopi}

\section{HASIL DAN PEMBAHASAN}

Dari hasil analisis statistik diperoleh bahwa suhu penyangraian yang berbeda berpengaruh nyata terhadap warna seduhan bubuk kopi. Hasil uji lanjut DNMRT pada taraf $\alpha$ 5\% terhadap skor nilai rata-rata warna seduhan bubuk kopi pada suhu penyangraian yang berbeda dapat dilihat pada Tabel 1.

Tabel 1. Skor nilai rata-rata warna seduhan bubuk kopi dengan suhu penyangraian yang berbeda.

\begin{tabular}{ccc}
\hline Perlakuan & Skor & Warna * \\
\hline $180^{\circ} \mathrm{C}$ & $2,00 \mathrm{a}$ & Coklat \\
$200^{\circ} \mathrm{C}$ & $2,53 \mathrm{a}$ & Coklat \\
$220^{\circ} \mathrm{C}$ & $4,46 \mathrm{~b}$ & Coklat Kehitaman \\
$240^{\circ} \mathrm{C}$ & $6,80 \mathrm{c}$ & Hitam \\
\hline
\end{tabular}

Keterangan : Angka-angka yang diikuti huruf kecil yang sama berbeda tidak nyata menurut uji DNMRT taraf $\alpha$ 5\% * : Interpretasi Skor Skala Likert 5 Skala

Dari Tabel 1 dapat dilihat bahwa warna seduhan bubuk kopi yang disangrai dengan suhu $240^{\circ} \mathrm{C}$ memberikan skor tertinggi yaitu (6.80) yang menghasilkan warna hitam, hasil ini berbeda nyata bila dibandingkan dengan perlakuan lainnya. Perlakuan penyangraian pada suhu $180^{\circ} \mathrm{C}$ menunjukkan skor terendah yaitu (2.00) berwarna coklat, hasil ini berbeda tidak nyata bila dibandingkan dengan perlakuan menggunakan suhu $200^{\circ} \mathrm{C}$ yaitu (2.53) yang menujukkan warna coklat.

Dari hasil penelitian menunjukkan semakin tinggi suhu penyangraian, warna seduhan bubuk kopi semakin hitam. Warna seduhan bubuk kopi dengan suhu penyangraian $180^{\circ} \mathrm{C}-200^{\circ} \mathrm{C}$ menghasilkan warna coklat, pada suhu 
$220^{\circ} \mathrm{C}$ menghasilkan warna coklat kehitaman, dan pada suhu $240^{\circ} \mathrm{C}$ menghasilkan warna hitam. Perubahan fisik dan kimia pada biji kopi selama penyangraian diawali dengan terjadinya penguapan air (warna biji kopi hijau), selanjutnya seiring dengan peningkatan suhu terjadi perubahan warna biji kopi menjadi kuning kecoklatan, pada saat ini mulai terjadi reaksi Maillard (reaksi gula reduksi + asam amino). Mulai suhu $200^{\circ} \mathrm{C}$ warna biji kopi berubah menjadi coklat karena terjadinya proses karamelisasi (reaksi + gula-gula), dan pada suhu $205^{\circ} \mathrm{C}$ terjadi reaksi pemecahan rantai karbon (warna biji kopi hitam). Menurut Sivetz (1963) dalam Purnamayanti, Gunadya dan Arda (2017), selama proses penyangraian terjadi perubahan-perubahan yang dapat dibedakan secara visual. Perubahan warna tersebut mulai dari warna hijau, menjadi coklat kayu manis, kemudian hitam dengan permukaan berminyak. Menurut Sari (2001) dalam Purnamayanti, Gunadya dan Arda (2017), faktor lain yang mempengaruhi warna seduhan kopi yang dihasilkan karena adanya proses karamelisasi gula yang menimbulkan warna coklat tua.

\section{Aroma Seduhan Bubuk Kopi}

Dari hasil analisis statistika diperoleh suhu penyangraian berpengaruh nyata terhadap aroma seduhan bubuk kopi. Hasil uji lanjut DNMRT pada taraf $\alpha$ 5\% terhadap skor nilai rata-rata aroma seduhan bubuk kopi dengan suhu penyangraian yang berbeda dapat dilihat pada Tabel 2 .

Tabel 2. Skor nilai rata-rata aroma seduhan bubuk kopi dengan suhu penyangraian yang berbeda.

\begin{tabular}{ccc}
\hline Perlakuan & Skor & Aroma * \\
\hline $180^{\circ} \mathrm{C}$ & $4,53 \mathrm{a}$ & Agak disukai \\
$200^{\circ} \mathrm{C}$ & $4,53 \mathrm{a}$ & Agak disukai \\
$220^{\circ} \mathrm{C}$ & $4,80 \mathrm{a}$ & Agak disukai \\
$240^{\circ} \mathrm{C}$ & $7,20 \mathrm{~b}$ & Disukai \\
\hline
\end{tabular}

Keterangan : Angka-angka yang diikuti huruf kecil yang sama berbeda tidak nyata menurut uji DNMRT taraf $\alpha$ 5\%

* : Interpretasi Skor Skala Likert 5 Skala

Dari Tabel 2 dapat dilihat bahwa aroma seduhan bubuk kopi yang disangrai dengan suhu $240^{\circ} \mathrm{C}$ memberikan skor yang tertinggi yaitu (7.20) memberikan aroma disukai, hal ini berbeda nyata bila dibandingkan dengan perlakuan suhu penyangraian lainnya. Perlakuan penyangraian $180^{\circ} \mathrm{C}$ menujukkan skor terendah dengan nilai (4.53) yang memberikan aroma agak disukai, hasil ini berbeda tidak nyata bila di bandingkan dengan $220^{\circ} \mathrm{C}$.

Penilaian aroma seduhan bubuk kopi menunjukkan bahwa semakin tinggi suhu penyangraian, aroma seduhan bubuk kopi semakin disukai oleh panelis. Aroma seduhan bubuk kopi yang disukai oleh panelis adalah bubuk kopi hasil penyangraian dengan suhu $240^{\circ} \mathrm{C}$. Hal ini terjadi karena seduhan bubuk kopi yang disangrai pada suhu $240^{\circ} \mathrm{C}$, aroma yang dihasilkan sudah sempurna. Sedangkan seduhan bubuk kopi yang disangrai pada suhu $180^{\circ} \mathrm{C}, 200^{\circ} \mathrm{C}$, dan $220^{\circ} \mathrm{C}$, tidak disukai oleh panelis karena aroma yang dihasilkan masih terasa aroma biji kopi kurang matang.

Menurut Sivertz (1972) dalam Ayu, Ida dan Arda (2017), aroma seduhan dari bubuk kopi muncul akibat senyawa volatile yang tertangkap oleh media penciuman manusia.. Senyawa volatile yang bersifat mudah menguap seperti aldehida, keton, furfural, asam, ester, dan alcohol ( Mulato et al, 2006). Senyawa volatile yang berpengaruh pada aroma bubuk kopi sangrai dibentuk dari reaksi millard atau reaksi browing non enzimatik, degrarasi asam amino bebas, degrarasi trigonelin, degrarasi gula dan senyawa fenolik. Semakin banyak komponen senyawa volatile yang larut dalam air saat penyeduhan semakin tajam aroma yang dihasilkan.

\section{Citarasa Seduhan Bubuk Kopi}

Dari hasil analisis statistika diperoleh bahwa suhu penyangraian berpengaruh nyata terhadap citarasa seduhan bubuk kopi. Hasil uji DNMRT pada taraf $\alpha$ 5\%. terhadap skor nilai rata-rata citarasa seduhan bubuk kopi penyangraian yang berbeda dapat dilihat pada Tabel 3.

Tabel 3. Skor nilai rata-rata citarasa seduhan bubuk kopi dengan suhu penyangraian yang berbeda.

\begin{tabular}{ccc}
\hline Perlakuan & Skor & Citarasa* \\
\hline $180^{\circ} \mathrm{C}$ & $4,53 \mathrm{a}$ & Agak disukai \\
$200^{\circ} \mathrm{C}$ & $4,60 \mathrm{a}$ & Agak disukai \\
$220^{\circ} \mathrm{C}$ & $4,60 \mathrm{a}$ & Agak disukai \\
$240^{\circ} \mathrm{C}$ & $6,53 \mathrm{~b}$ & Disukai \\
\hline
\end{tabular}

Keterangan : Angka-angka yang diikuti huruf kecil yang sama berbeda tidak nyata menurut uji DNMRT taraf $\alpha 5 \%$ * : Interpretasi Skor Skala Likert 5 Skala

Dari Tabel 3 dapat dilihat bahwa citarasa seduhan bubuk kopi yang disangrai dengan suhu penyangraian $240^{\circ} \mathrm{C}$ memberikan skor yang tertinggi yaitu $(6,53)$ yang menghasilkan penilaian citarasa disukai. Hasil ini berbeda nyata bila dibandingkan dengan perlakuan pada suhu penyangraian lainnya. Perlakuan penyangraian $180^{\circ} \mathrm{C}$ menunjukkan skor 
terendah $(4,53)$ yang memberikan hasil penilaian citarasa agak disukai. Hasil ini berbeda tidak nyata bila dibandingkan dengan suhu $200 \mathrm{C}-220^{\circ} \mathrm{C}$.

Citarasa seduhan bubuk kopi yang disangrai selama 20 menit dengan menggunakan suhu yang berbeda menghasilkan citarasa agak disukai hingga disukai oleh penelis. Citarasa yang paling disukai oleh panelis adalah seduhan bubuk kopi yang disangrai pada suhu $240^{\circ}$ C. Menurut penelitian Sari (2001) dalam Purnamayanti, Gunadya, Arya (2017), citarasa kopi dipengaruhi oleh hasil degrarasi beberapa senyawa seperti karbohidrat, alkaloid, asam klorogenat, senyawa volatil (aldehida, keton, furfural, asam, ester, dan alcohol), dan trigonelin. Selama proses penyangraian mengakibatkan senyawa karbohidrat terdegrarasi menjadi glukosa dan gula-gula sederhana yang menghasilkan rasa manis. Akaloid adalah kafein yang mengalami sublimasi membentuk kafeol. Kafein memiliki rasa pahit yang kuat dan dan rasa asam dari klorogenat dan trigonelin..

\section{Kepahitan Seduhan Bubuk Kopi}

Dari hasil analisis statistika diperoleh bahwa suhu penyangraian berpengaruh nyata terhadap kepahitan seduhan bubuk kopi. Hasil uji lanjut DNMRT pada taraf $\alpha$ 5\% terhadap skor nilai rata-rata kepahitan seduhan bubuk kopi dapat dilihat pada Tabel 4.

Tabel 4. Skor nilai rata-rata kepahitan seduhan bubuk kopi dengan suhu penyangraian yang berbeda.

\begin{tabular}{ccc}
\hline Perlakuan & Skor & Kepahitan* \\
\hline $180^{\circ} \mathrm{C}$ & $3,80 \mathrm{a}$ & Agak pahit \\
$200^{\circ} \mathrm{C}$ & $4,06 \mathrm{a}$ & Agak pahit \\
$220^{\circ} \mathrm{C}$ & $4,46 \mathrm{a}$ & Agak pahit \\
$240^{\circ} \mathrm{C}$ & $6,73 \mathrm{~b}$ & Pahit \\
\hline
\end{tabular}

Keterangan : Angka-angka yang diikuti huruf kecil yang sama berbeda tidak nyata menurut uji DNMRT taraf $\alpha$ 5\%

* : Interpretasi Skor Skala Likert 5 Skala

Dari Tabel 4 dapat dilihat bahwa kepahitan seduhan bubuk kopi yang disangrai dengan suhu penyangraian $240^{\circ}$ $\mathrm{C}$ menujukkan skor tertinggi yaitu (6.73) yang menghasilkan nilai pahit, hasil ini berbeda nyata bila dibandingkan dengan perlakuan lainnya. Pada suhu penyangraian $180^{\circ} \mathrm{C}$ menujukkan skor penilaian yang terendah yaitu (3.80) yang menghasilkan penilaian agak pahit, Hasil ini berbeda tidak nyata bila dibandingkan dengan suhu $200^{\circ} \mathrm{C}$ dan $220^{\circ} \mathrm{C}$.

Dari hasil pengujian panelis menunjukkan bahwa semakin tinggi suhu penyangraian, tingkat kepahitan seduhan bubuk kopi semakin pahit. Tingkat kepahitan tertinggi seduhan bubuk kopi diperoleh pada penyangraian dengan suhu $240^{\circ} \mathrm{C}$. Rasa pahit pada seduhan bubuk kopi ditentukan alkaloid yaitu kafein yang mengalami sublimasi membentuk kafeol (Sari 2001) dalam Purnamayanti, Gunadya dan Arda (2017). Dari hasil penelitian Agustina et al (2019 kadar kafein pada biji kopi semakin meningkat dengan semakin tingginya suhu penyangraian. Hal ini terjadi karena terurainya zat cair yang berikatan dengan kafein sehingga mempermudah ekstraksi kafein dari kopi. Sejalan dengan penelitian Agusanti (2011). menyatakan bahwa semakin tinggi suhu penyangraian maka kadar kafein juga semakin meningkat, hal ini disuga karena terurainya zat cair dan zat asam sehingga jumlah kandunungan kafein.

\section{Kesukaan Seduhan Bubuk Kopi}

Dari hasil analisis statistika diperoleh bahwa penggunaan suhu penyangraian berpengaruh nyata terhadap kesukaan seduhan bubuk kopi. Hasil uji lanjut DNMRT pada taraf $\alpha 5 \%$ terhadap skor rata-rata nilai kesukaan seduhan bubuk kopi dapat dilihat pada Tabel 5 .

Tabel 5. Skor rata-rata nilai kesukaan seduhan bubuk kopi dengan suhu penyangraian yang berbeda.

\begin{tabular}{ccc}
\hline Perlakuan & Skor & Kesukaan* \\
\hline $180^{\circ} \mathrm{C}$ & $4,40 \mathrm{a}$ & Agak disukai \\
$200^{\circ} \mathrm{C}$ & $4,60 \mathrm{a}$ & Agak disukai \\
$220^{\circ} \mathrm{C}$ & $5,20 \mathrm{a}$ & Agak disukai \\
$240^{\circ} \mathrm{C}$ & $6,66 \mathrm{~b}$ & Disukai \\
\hline
\end{tabular}

Keterangan : Angka-angka yang diikuti huruf kecil yang sama berbeda tidak nyata menurut uji DNMRT taraf $\alpha$ 5\% * : Interpretasi Skor Skala Likert 5 Skala

Dari Tabel 5 dapat dilihat bahwa kesukaan seduhan bubuk kopi yang disangarai dengan suhu penyangraian $240^{\circ}$ $\mathrm{C}$ memberikan penilaian tertinggi $(6,66)$ yaitu disukai. Hasil ini berbeda nyata bila dibandingkan dengan perlakuan pada suhu penyangraian $180^{\circ} \mathrm{C}$ menunjukkan skor terendah dengan nilai $(4,40)$ yang memberikan hasil penilaian agak disukai. Hasil ini berbeda tidak nyata bila dibandingkan dengan suhu $200^{\circ} \mathrm{C}$ dan $220^{\circ} \mathrm{C}$. 
Tingkat kesukaan seduhan bubuk kopi yang paling disukai oleh panelis adalah dari biji kopi yang disangrai pada suhu $240^{\circ} \mathrm{C}$, sedangkan seduhan bubuk kopi yang disangrai pada suhu lainnya tidak disukai hingga agak disukai. Hal ini terjadi karena biji kopi yang disangrai pada suhu $240^{\circ} \mathrm{C}$ telah mengalami perubahan fisik dan kimiawi secara sempurna. Hal ini ditandai dengan munculnya warna hitam, aroma yang wangi dan cita rasa serta kepahitan yang khas yang disukai panelis. Menurut Yusanto dan Mulato (2002), senyawa kafein memberikan citarasa yang khas sehingga menjadikan kopi sebagai minuman yang digemari banyak orang.

\section{Keasaman (pH) Bubuk Kopi}

Dari hasil analisis statistika diperoleh bahwa suhu penyangraian berpengaruh nyata terhadap pH bubuk bubuk kopi. Hasil uji lanjut DNMRT pada taraf $\alpha$ 5\% terhadap skor rata-rata nilai $\mathrm{pH}$ bubuk kopi dapat dilihat pada Tabel 6.

Tabel 6. Nilai rata-rata $\mathrm{pH}$ seduhan bubuk kopi dengan suhu penyangraian yang berbeda.

\begin{tabular}{cc}
\hline Perlakuan & $\mathrm{pH} \%$ \\
\hline $180^{\circ} \mathrm{C}$ & $5,3 \mathrm{a}$ \\
$200^{\circ} \mathrm{C}$ & $5,5 \mathrm{~b}$ \\
$220^{\circ} \mathrm{C}$ & $5,6 \mathrm{~b}$ \\
$240^{\circ} \mathrm{C}$ & $5,9 \mathrm{c}$ \\
\hline
\end{tabular}

Keterangan : Angka-angka yang diikuti huruf kecil yang sama berbeda tidak nyata menurut uji DNMRT taraf $\alpha 5 \%$

Dari Tabel 6 dapat dilihat bahwa $\mathrm{pH}$ bubuk kopi dengan suhu penyangraian $240^{\circ} \mathrm{C}$ memberikan nilai $\mathrm{pH}$ tertinggi yaitu $(5,9)$. Hasil ini berbeda nyata bila dibandingkan dengan perlakuan suhu penyangraian lainnya. Suhu perlakuan $180^{\circ} \mathrm{C}$ memberikan $\mathrm{pH}$ lebih rendah $(5,3)$. Hasil ini berbeda nyata dengan perlakuan lainnya.

Dari hasil penelitian menunjukkan bahwa semakin tinggi suhu penyangraian, $\mathrm{pH}$ bubuk kopi semakin tinggi (keasamannya menurun). Menurut Mulato (2002) dalam Purnamayanti, Gunadya, Arya (2017), yang menyatakan bahwa biji kopi secara alami mengadung berbagai jenis senyawa volatil seperti aldehida, furfural, keton, alkohol, ester, asam format dan asam asetat yang mempunyai sifat mudah menguap. Senyawa-senyawa ini akan semakin banyak mengalami penguapan seiring dengan semakin tinggi suhu dan waktu penyangraian. Penurunan nilai keasaman pada bubuk kopi disebabkan semakin tinggi suhu penyangraian semakin banyak senyawa asam klorogenat dan asam karboksilat yang menguap pada saat kopi disangrai. Menurut Yusdiali et al (2008), pH bubuk kopi akan meningkat seiring dengan meningkatnya suhu penyangraian, perubahan nilai $\mathrm{pH}$ pada bubuk kopi cenderung naik menuju ke nilai $\mathrm{pH}$ netral.

\section{Kadar Air Bubuk Kopi}

Dari hasil analisis statistika diperoleh bahwa suhu penyangraian berpengaruh nyata terhadap kadar air bubuk kopi. Dari hasil uji DNMRT dengan taraf $\alpha$ 5\%, terhadap kadar air bubuk kopi dapat dilihat pada Tabel 7.

Tabel 7. Nilai rata-rata kadar air bubuk kopi dengan suhu penyangraian yang berbeda.

\begin{tabular}{cc}
\hline Perlakuan & Kadar air(\% $)$ \\
\hline $180^{\circ} \mathrm{C}$ & $2,1 \mathrm{a}$ \\
$200^{\circ} \mathrm{C}$ & $1,0 \mathrm{~b}$ \\
$220^{\circ} \mathrm{C}$ & $1,3 \mathrm{~b}$ \\
$240^{\circ} \mathrm{C}$ & $0,3 \mathrm{c}$ \\
\hline
\end{tabular}

Keterangan : Angka-angka yang diikuti huruf kecil yang sama berbeda tidak nyata menurut uji DNMRT taraf $\alpha$ 5\%

Dari Tabel 9 dapat dilihat bahwa kadar air bubuk kopi yang disangrai pada suhu $240^{\circ} \mathrm{C}$ lebih rendah $(0.3 \%)$, dimana kadar air ini berbeda nyata dengan kadar air bubuk kopi yang disangrai pada suhu lainnya. Tetapi kadar air bubuk kopi yang disangrai pada suhu $180^{\circ} \mathrm{C}, 200^{\circ} \mathrm{C}$, dan $220^{\circ} \mathrm{C}$, berbeda tidak nyata satu dengan lainnya.

Dari hasil pengamatan menujukkan bahwa semakin tinggi suhu penyangraian, kadar air bubuk kopi semakin rendah. Hal ini terjadi karena selama penyangraian, semakin tinggi suhu penyangraian semakin banyak air yang diuapkan dari biji kopi. Selama penyangraian terjadi perpindahan panas dari media sangrai ke biji kopi. Perpindahan panas ini mengakibatkan terjadinya perubahan massa air dari biji kopi menjadi uap air. Hal ini sejalan dengan penelitian Purnamayanti, Gunadya, Arya (2017), bahwa semakin lama proses penyangraian kadar air biji kopi semakin menurun. Artinya proses penyangraian lebih lama mengakibatkan suhu penyangraian juga akan mengalami peningkatan sehingga kadar air dari biji kopi semakin banyak yang diuapkan 


\section{KESIMPULAN}

Berdasarkan hasil penelitian dan pembahasan di atas dapat ditarik kesimpulan sebagai berikut :

Suhu penyangraian biji kopi yang berbeda menghasilkan karakteristik mutu organoleptik yang berbeda nyata pada seduhan bubuk kopi robusta. Penyangraian biji kopi pada suhu $240^{\circ} \mathrm{C}$, menghasilkan penilaian organoleptik tertinggi pada seduhan bubuk kopi baik dari warna, aroma, citarasa, kepahitan, kesukaan. Sedangkan pH lebih tinggi dan kadar air lebih rendah pada bubuk kopi.

\section{DAFTAR PUSTAKA}

Agusanti Y. 2011. Analisa Mutu Bubuk Kopi Robusta (Coffea canephora) pada CV Bintang makmur. Skripsi. Blangk Bintang. Aceh Besar. Program Studi Teknik Pertanian, Fakultas Pertanian, Universitas Syah Kuala, banda Aceh.

Agustina R, Nurba D, Windy A dan Rika S. 2019. Pengaruh Suhu dan Lama Penyangraian Terhadap Sifat Fisik-Kimia Kopi Arabika dan Kopi Robusta. Fakultas Pertanian, Universitas Syiah Kuala, Banda Aceh. Prosiding Seminar Nasional, ISBN : 978-602-52982-1-9.

Mulato, S., S. Widyotomo, Misnawi, \& E. Suharyanto, 2006. Teknologi Proses dan Pengolahan Produk Primer dan Sekunder Kopi Jember : Pusat Penelitian Kopi dan Kakao.

Natawidjaya. H., M. Unggul Ametung., Edi Suharyanto., Sri Mulato., Dedi (2012). Pedoman Teknis penanganan pasca panen Kopi. Direktorat pasca panen dan pembinaan Usaha. Direktorat Jendral Perkebunan. Kementrian Pertanian.

Prastowo, B., E. Karnawati, Rubijo, Siswanto, C. Indrawanto, S.J. Munarso (2010). Budidaya dan Pasca panen Kopi. Pusat Penelitian dan Pengembangan Perkebunan.

Purnamayanti, NPU, I.B.P. Gunadya, G. Arya (2017). Pengaruh Suhu dan lama Penyangraian Terhadap karakteristik Fisik dan Mutu Sensori Kopi Arabika (Coffea Arabica L). Jurnal Beta (Biosistem dan Teknik Pertanian) Program Studi Teknik Pertanian, fakultas Pertanian Universitas Udayana. http://ojs.unud.ac.id/index.php/beta Volume 5 No 2. Septeber 2017

Rahardjo, P. 2012. Panduan Budidaya dan Pengolahan Kopi Arabika dan Robusta. Penebar Swadaya: Jakarta.

Yusanto dan Mulato (2001. Pengolahan dan Komposisi Kimia Biji Kopi, Pengaruhnya terhadap citarasa seduhan. Materi Pelatihan Uji Citarasa Kopi. Pusat Penelitian Kopi dan Kakao Indonesia, Jember.

Yusdiali W, Mursalim, Tulliza IS. 2008. Pengaruh Suhu dan Lama Penyangraian Terhadap Tingkat Kadar air dan Keasaman Kopi Robusta. Jakarta (ID): Erlangga. 